\title{
A!
}

This is an electronic reprint of the original article.

This reprint may differ from the original in pagination and typographic detail.

Hodouin, Daniel; Jämsä-Jounela, Sirkka-Liisa; Carvalho, Teresa C.; Bergh, Luis

\section{State of the art and challenges in mineral processing control}

\section{Published in:}

Control Engineering Practice

DOI:

10.1016/S0967-0661(01)00088-0

Published: 01/01/2001

Document Version

Peer reviewed version

\section{Please cite the original version:}

Hodouin, D., Jämsä-Jounela, S-L., Carvalho, T. C., \& Bergh, L. (2001). State of the art and challenges in mineral processing control. Control Engineering Practice, 9(9), 995-1005. https://doi.org/10.1016/S0967-0661(01)000880

This material is protected by copyright and other intellectual property rights, and duplication or sale of all or part of any of the repository collections is not permitted, except that material may be duplicated by you for your research use or educational purposes in electronic or print form. You must obtain permission for any other use. Electronic or print copies may not be offered, whether for sale or otherwise to anyone who is not an authorised user. 


\title{
State of the art and challenges in mineral processing control
}

\author{
D. Hodouin ${ }^{\text {a }}$ S.-L. Jämsä-Jounela ${ }^{\text {, }}$ M. T. Carvalho ${ }^{c}$, L. Bergh ${ }^{d}$ \\ ${ }^{a}$ Department of Mining and Metallurgy, Laval University, Sainte-Foy, Quebec City, Canada, GIK 7P4 \\ ${ }^{b}$ Department of Chemical Technology, Helsinki University of Technology, Espoo, Finland \\ ${ }^{c}$ CVRM-Centro de Geo-sistemas, IST, Av. Rovisco Pais, Lisboa, Portugal \\ ${ }^{d}$ Chemical Engineering Department, Santa Maria University, Valparaiso, Chile
}

\section{Abstract}

The objective of process control in the mineral industry is to optimise the recovery of the valuable minerals, while maintaining the quality of the concentrates delivered to the metal extraction plants. The paper presents a survey of the control approaches for ore size reduction and mineral separation processes. The present limitations of the measurement instrumentation are discussed, as well as the methods to upgrade the information delivered by the sensors. In practice, the overall economic optimisation goal must be hierarchically decomposed into simpler control problems. Model-based and AI methods are reviewed, mainly for grinding and flotation processes, and classified as mature, active or emerging. (C) 2001 Elsevier Science Ltd. All rights reserved.

Keywords: Mineral processing; Process control; Optimisation; Data processing

\section{Introduction}

A raw ore cannot be used as such as a final product for industrial or commercial uses. It needs to be treated for preparing a usable material that can be either a specific mineral, as it is in the orebody, or more usually a metal, an alloy, or a compound such as an oxide. Although the steps of the chain of transformation which lead to the final metal is a technically coherent sequence of processes, the present study is limited to the physical treatments of ores (mineral processing or MP in the following text), leaving chemical transformations involved in hydro-, pyro-, and electrometallurgy to other analyses. The objective of this contribution is to make a survey of the progresses and challenges in the field of automatic control of the two main stages of an MP plant, namely ore comminution and mineral separation processes.

As in any other primary industry, developments have been made in hardware (sensors, data transmission systems, computers) as well as in software (data management, process models, control algorithms). However, problems inherent to the high level of complexity of the processed material are still there, leaving process engineers with more questions than answers. The survey begins by defining the overall control objective for an MP plant, showing that it must be broken down into simpler control tasks. Then, since a good understanding and representation of the 
phenomena involved in an MP process is a key prerequisite for designing control strategies, the next section of the paper discusses MP process models. Another essential ingredient for MP control is information about the process states. The survey discusses various aspects of this specifically critical stage in a control strategy: measurement instrumentation, data reconciliation, pattern recognition, fault detection and diagnosis, soft sensors, process and controller performance monitoring. Then knowledge-based control strategies for breakage and flotation processes are systematically reviewed and discussed. Finally, a conclusion tries to qualify as mature, active, or emerging the methods used to solve specific control problems of MP operations, and makes some comments on the human resources aspects of MP plant control.

\section{Control objectives}

The aim of an MP operation is to concentrate a raw ore for the subsequent metal extraction stage. Usually, the valuable minerals are first liberated from the ore matrix by comminution and size separation processes, and then separated from the gangue using processes capable of selecting the particles according to their physical or chemical properties, such as surface hydrophobicity, specific gravity, magnetic susceptibility, and colour. The processes to be controlled in MP can thus be classified into three different categories:

- Minerals liberation processes (crushing, grinding and size classification)

- Minerals separation processes (flotation, magnetic or gravimetric classification)

- Peripheral processes such as feeders, pumps, conveyors, thickeners, dryers and systems for concentrate shipping, tailings disposal, mine backfilling, effluent treatment, reagent dosage.

The overall control objective of an MP plant, as depicted in Fig. 1, is to prepare a concentrate which meets the requirements defined in the buyer-seller contract, while maximising the net revenue of the concentrator. Ideally, real-time plant-wide optimisation should be the right approach to MP plant control (Herbst, Pate, Flores, \& Zarate, 1995), i.e. the adjustment of the operating conditions of the various units as a function of the raw ore properties and feed rate, metal market prices and energy and reagent costs. The complexity of defining optimisation criteria and optimal operating conditions has been extensively discussed by Kelly (1991). Bascur (1991) has proposed a profitability concept defined by relating profit, recovery, tonnage and grind in order to co-ordinate the overall grinding and flotation objectives. Morrison (1993) also discussed various optimisation strategies, such as minimum energy and maximum recovery philosophies, and studied the impact of the grinding circuit tuning on the metal recovery. Usually these objectives require some trade-off between the concentrate grade and tonnage, the impurities contents and the operating costs (Sosa-Blanco, Hodouin, Bazin, Lara-Valenzuela, \& Salazar, 2000). 


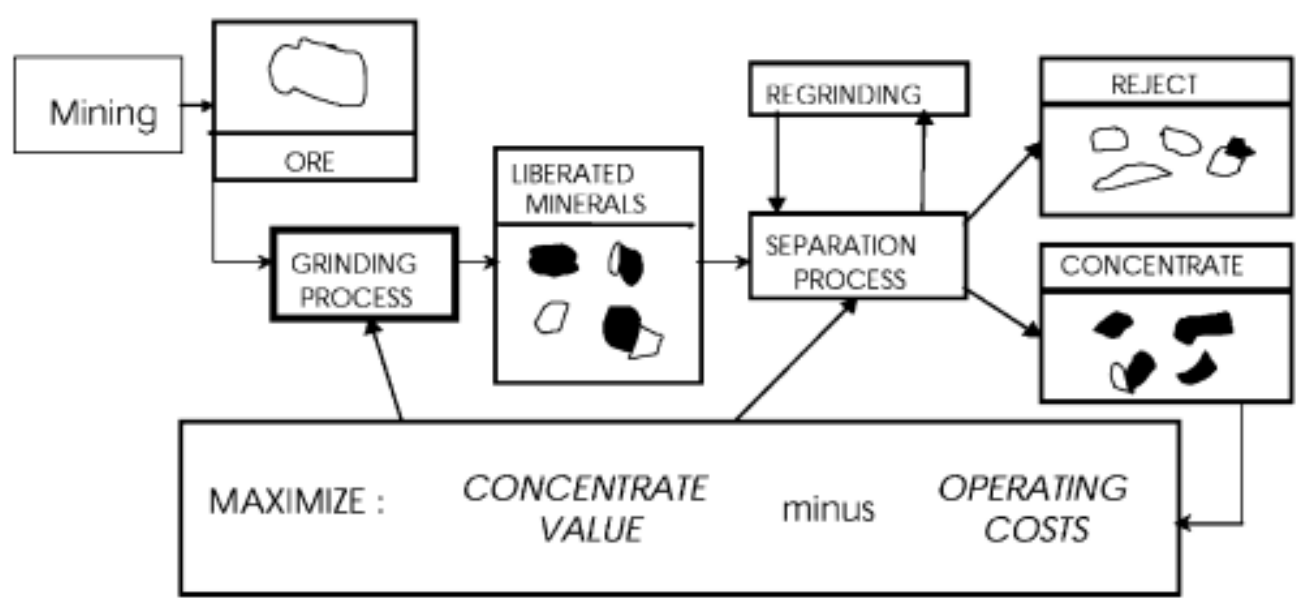

Fig. 1. Ideal scheme of a strategy for economic optimisation of a mineral processing plant

\section{Process models}

An essential feature of control and optimisation strategies is the availability of mathematical models that accurately describe the steady-state and dynamic characteristics of the process in the whole operating range, including its non-linear behaviour. Satisfactory mathematical models are not frequently available. A first reason is that an ore is an exceptionally complex system compared to material such as those processed by the chemical, cement or paper industries. It contains intricately mixed minerals with randomly varying properties (grain size, mineral content and associations, micro-cracks and surface characteristics distribution). A second reason is that the physics and chemistry of the subprocesses involved are poorly understood.

However, progress has been made for SAG milling modelling (Valery and Morell, 1995). Modelling of grinding media motion using discrete element methods is now a current practice (Moys, van Nierop, van Tonder, \& Glover, 2000; Inoue \& Okaya, 2000). It is mainly used for a better understanding of load behaviour, breakage mechanisms and energy dissipation, and for design purpose. It might help in the future to control comminution equipments.

In the flotation area, the well-established role of bubble surface area (Bascur, 2000), which has been forgotten for years, is now at last recognized and incorporated into models (Finch et al., 1999). Micro-mechanisms such as the rate of flotation as a function of particle size (Schena \& Gochin, 2000), interactions of chemical species of the liquid phase and particle surfaces, attraction forces between bubbles and particles (Yoon, 2000) and mechanisms in the froth are better understood. Finally, efforts have been made for plant-wide simulation (Sosa-Blanco, Hodouin, \& Bazin, 1999; Herbst \& Pate, 2000).

\section{Information acquisition for control purposes}

MP optimisation and control cannot be performed without a minimum amount of information on the input disturbances (the material properties), the process states, and the final product quality. This is in fact the bottleneck of MP control. The operating strategy efficiency is totally dependent 
upon the quality of the information which is used, since, on the one hand, it is used to build the knowledge encapsulated in the models which the control strategy is based upon, and, on the other hand, it is the input to the real-time optimisation and control algorithms.

\subsection{Instrumentation}

Measurement of ore composition, particle size distribution and flowrates is central in the control of MP operations. Adequate instrumentation is also available for less ore specific properties such as levels, motor power, rotation speed, $\mathrm{pH}$, slurry density. However, essential properties such as grindability, mineral texture, liberation degree, surface activity, slurry rheology, grinding media size distribution, bubble size distribution and loading are extremely difficult to measure and even to infer from other measurements.

There are various devices for particle size measurement in the fine size range. They can mechanically measure the particle size or infer it through physical phenomena such as laser diffraction or ultra-sound absorption. In the coarse size range, video images of the flowing particulate material are now processed to extract information on particle size. Measurements can be obtained during unloading trucks of run of mine (Herbst \& Blust, 2000), or, more usually from pictures of material on conveyors (Maerz \& Palangio, 2000; Morrison, 2000).

X-ray fluorescence is the universal method for on-line solid composition measurement in MP plants. Equipment vendors now offer more efficient, compact, flexible and reliable devices. The sampling device as well as the technique for presenting the sample at the analyser window is critical, since the very small quantity of ore to be analysed must be representative of tons of an inherently heterogeneous material (Mirabedini \& Hodouin, 1998). The reliability of the method is also strongly related to the quality of the calibration of the method (Leroux \& Franklin, 1994). Xray diffraction is proposed as a potential technique to monitor the mineral composition of the solid phase (Nikolov \& Madsen, 2000).

Measurement of the degree of liberation of the minerals, a property directly related to the particle composition distribution as a function of particle size, is an extremely complex problem. There is no available online instrument, however off-line 1D or 2D measurement techniques, based on processing of optical or SEM images (back scattered electrons or X-ray spectra) are becoming faster and more efficient (Gu \& Guerney, 1999). Also very significant progresses have been made for solving the problem of 3D reconstruction of the particle properties (Barbery, 1991; King \& Schneider, 2000; Spencer \& Sutherland, 2000).

In the grinding field, new devices are tested to monitor mill noise, shell vibrations and forces applied to lifters to infer properties such as ball and slurry loads, slurry viscosity, wear, shape and location of the hold-up (Spencer, Campbell, Weller, \& Liu, 2000). The main difficulty is to relate the recorded signals to physical properties of the system.

In the flotation field, many investigations have been made for froth image utilisation (Bonifazi, Serranti, Volpe, \& Zuco, 1999; Cipriano, Guarini, Soto, Briceno, \& Mery, 1997; van Deventer Bezuidenhout, \& Moolman, 1997; Hyotyniemi \& Ylinen, 1998). However, the captured information is quite complex and requires the development of correlation equations with process 
variables that have to be controlled. Interesting sensors are under development for flotation columns for measuring the air hold-up, the location of the froth-pulp interface, and the water split bias (del Villar, Grégoire, \& Pomerleau, 1999a, b; Finch \& Dobby, 1990).

Finally, the communication hardware and software between the measurement devices and the data processing units are currently undergoing rapid changes in the MP industry (see the survey paper by Jämsä-Jounela, 2000).

\subsection{Data management systems}

Real-time and historical information is useful for global plant optimisation. Smart data management systems are required for efficient communication between the business staff (information on metal inventories, costs, production objective, equipment availability, etc.), the process engineers (information for production optimisation and control), the laboratory (quality control), the environment department, and the operators of the various units (mining, crushing, grinding, mineral separation, dewatering, tailings disposal, reagent preparation, mine back-filling, concentrate shipping, etc.). In addition to the data exchange facilities, the format of the information must be easily adapted to the various objectives of data processing (local control, loop tuning, mass balance calculation, process modelling, maintenance and trouble-shooting, performance indicator display, real-time optimisation, etc.). Bascur (1993) and Bascur and Kennedy (1999), describe extensively the available data management architectures and their benefits.

\subsection{Data reconciliation}

Due to the inherent inaccuracies of the measurements made on the multiphase materials processed in MP, the raw data is delivered by the sensors, such as flowrates, chemical assays, and particle size distributions, contains errors. Data reconciliation procedures are used to correct measurements and make it coherent with prior knowledge about the process. Frequently, mass conservation equations are used as a basic model to reconcile redundant data with prior knowledge constraints (Crowe, 1996; Romagnoli \& Sanchez, 2000; Narasimhan \& Jordache, 1999). At the same time, data reconciliation techniques are used to infer unmeasured process variables such as flowrate and composition of internal streams of a complex MP unit.

The off-line reconciliation methods are mature and various computer packages are now available. On-line applications to stationary processes are active, while methods which make a trade-off between the model uncertainties and the measurement errors are now emerging (Makni, Hodouin, \& Bazin, 1995a; Hodouin \& Makni, 1998). The evaluation of the sampling errors has been refined, thus leading to a more objective tuning of the weighting factors (Hodouin, Mirabedini, Makni, \& Baxin, 1998). Dynamic methods have been developed for real-time applications (Makni \& Hodouin, 1994; Makni, Hodouin, \& Bazin, 1995b). Reconciliation techniques are useful to calculate and display performance indices, such as concentrate grade and recovery, which, due to their better reliability, may improve manual or automatic process performance optimisation (Bazin \& Franklin, 1996; Hodouin, Bazin, \& Makni, 1997). Reconciliation methods based on artificial neural networks have also been proposed, but they do not offer either the same rigorous statistical and physical background or the same analytical tools for the evaluation of the results reliability (Du, Hodouin, \& Thibault, 1997b; Aldrich \& van Deventer, 1994). 


\subsection{Soft sensors and pattern recognition}

Historical or real-time sets of measurements on multivariable MP processes contain massive amount of information about the nature of the ore which is processed and about the behaviour of the operation. However, they are difficult to exploit because of the high number of available variables, their poor reliability and finally the lack of measurements for the most important properties as mentioned above. Soft sensors make use of simple models that calculate the values of the desired process variable as a function of other measured variables (Pérez, del Villar, \& Flament, 1993; Espinoza, Gonzalez, Casali, \& Ardiles, 1995; Carvalho \& Durão, 1999b; Du, del Villar, \& Thibault, 1997a). Statistical or AI techniques are active or emerging to extract, from data sets, pieces of information which may be useful for monitoring, predictive maintenance, diagnosis, control and optimisation. Principal component analysis (Tano, Samskög, Gärde, \& Skagerberg, 1993; Hodouin, Flament, \& Bazin, 1993a, Chap. 1; Hodouin, MacGegor, Hou, \& Franklin 1993b; Garrigues, Kettaneh, Wold, \& Bascur, 2000), cluster analysis (Espinoza et al., 1995), artificial neural nets (Aldrich, 1998) and fuzzy logic are typical tools which are active or emerging in the MP field. ANN has been applied at the Hitura and Kemi mines in Finland for the real-time identification of the type of ore being processed (Laine, Lappainen, \& Jämsä-Jounela, 1995; Jämsä-Jounela, Laine, \& Laurila, 1999a).

\subsection{Process monitoring, fault detection and isolation}

Failures of advanced data processing or control methods in the MP industry are either due to sensor faults or to a lack of maintenance of the algorithms in the plant. Process changes, new piping, sensor moving or failures are not reflected in the algorithms, which, thus, become unable to deliver what they have been designed for. It is mostly important that some kind of supervision be exerted on the methods to warrant their operating integrity. Some methods are emerging to detect either sensor biases or model inadequacies using multivariable statistical tests on the residuals of material balance constraints (Berton \& Hodouin, 2000; Hodouin \& Berton, 2000). ANN are active methods to detect and diagnose faults (Jämsä-Jounela, Toth, Kuitunen, \& Kampe, 1999b; Aldrich \& van Deventer, 1995). Supervision of the control strategy of flotation columns is used to detect sensor or operating problems using data validation and expert systems (Bergh \& Yianatos, 1999).

\subsection{Control loop monitoring}

In an MP operation there are hundreds of control loops. Most of them are local loops used for controlling actuators or inner loops in cascade control schemes. Typically, they are level, flow rate, and $\mathrm{pH}$ control loops. PI or PID algorithms, which are normally implemented at this lowest level of the plant control hierarchy, are to be tuned on a regular basis. Practically, a number of controllers are not well tuned and require new settings in order to improve the overall performance of the high level loops. The performance of the loops can be continuously monitored by processing data such as the deviations to the setpoints. When the loop performance is not acceptable, a more detailed analysis of the loop behaviour is performed using statistics such as auto-correlation and crosscorrelation functions, and power spectra. The minimum variance concept is quite a useful reference for control loop performance assessment (Stanfelj, Marlin, \& MacGregor, 1993; Spring, 1996), 
since it corresponds to the ideal behaviour of a control system. An illustration of the application of the technique to an MP operation is documented by Perry, Supomo, Mular, and Neale (2000).

\section{Optimisation and control}

Plant-wide optimisation is extremely difficult, due to the problem of linking grinding and separation processes through liberation measurement and modelling. As a consequence, comminution and separation processes are controlled with separate objectives and control strategies. Most of the time, only decentralized single-input-single-output (SISO) stabilising control is applied. It is a mature technology, widely used in the MP industry (Flintoff, 1995). The setpoints of the SISO loops are sometimes supervised by algorithms that maximize throughput at constant fineness of grind for comminution circuits, or maximize recovery at constant grade for separation circuits. Multi-objective optimisation is also possible in both cases.

For time variant and non-linear MP processes that undergo large unknown disturbances, these multiple SISO control loops sometimes exhibit poor performances. Three avenues are used to cope with these problems: multiple-input-multiple-output (MIMO) regulatory and supervisory optimising control based on mathematical models, AI techniques based on empirical or heuristics process models, and finally fuzzy logic or expert systems.

Despite some plant success stories, applied MIMO regulatory control can still be considered as an active or emerging technology, since, most of the time, studies in this area are limited to theoretical works based on simulated plants. Application of adaptive, non-linear and robust control theories to the MP processes can essentially be considered as emerging. One major problem related to the slow diffusion of advanced control techniques is that they constitute a rather hermetic corpus of knowledge with its own jargon, exclusive to those in the scientific and engineering communities who are versed in applied mathematics. To cope with that problem, an effort has been made to synthesise advanced linear control theories in a unified formalism, which is easier to teach to process engineers and easier to use for design purposes (Hodouin \& Desbiens, 1999; Desbiens, Hodouin, \& Plamondon, 2000). Another problem is the difficulty of establishing reliable mathematical process models, as already mentioned in Section 3.

A better situation prevails for the promising alternatives of AI techniques such as ANN (Stange, 1991), but most of the developments are still simulation studies. ANN methods offer inherent plasticity and robustness that well match the needs of the MP industry where model structures are uncertain. However, they have the drawbacks of empirical approaches. A comparison of the modelling capabilities of ANN and adaptive multilinear regression (Gepford, Spangler, Scott, \& Prisbrey, 2000) shows the limitations of the ANN technology and the need to use a combination of various tools for a better chance of success of the modelbased control algorithms. Expert systems tools based on heuristic rules and fuzzy logic reasoning have proven to be especially successful in the MP control applications and can be considered as a mature technology.

The state of the art and challenges in control will now be detailed separately for comminution and separation processes (mainly flotation). Peripheral processes control strategies are not discussed here. 


\subsection{Comminution processes}

Crushing, semi- or fully-autogenous grinding, rod and ball mill grinding are the most frequent comminution circuits. The fundamental objective of a grinding circuit is not size reduction, it is rather to liberate valuable minerals in such a way that the subsequent separation process can be operated at its maximum economic efficiency. In practice it is quite difficult to apply feedback control based on the economic value of the final concentrate (Fig. 1), for the reasons given above. Instead, control targets are defined for the particle size distribution (PSD) of the ground product on the basis of laboratory metallurgical tests.

Usually the PSD setpoint is selected from a compromise, since too fine a grind maximises the mineral liberation degree but is energetically very costly and induces separation problems, while too coarse a grind decreases concentrate grade because of the presence of middlings. Theoretically, the PSD should be matched to the separation process recovery as a function of the particle size (Sosa Blanco et al., 1999, 2000). Practically, the narrowest PSD in the size range of maximum recovery is obtained at the design or tuning stage of the grinding circuit, and the operation is controlled at a single target value defined by the percentage of particles finer than a given size.

Occasionally, a circuit may be controlled at constant production rate trying to maximise the product fineness, but most of the time it is controlled at a fixed setpoint of the fineness, trying to maximise the production, i.e. minimising the energy consumed per ton of ore (Lo, Oblad, \& Herbst, 1996). The maximisation of the production is normally obtained by fixing an optimal value of the circulating load, but it can be also obtained by real-time optimisation strategies. Crushing, FAG or SAG milling, and rod/ball milling circuits have quite significantly different control problems. They will be reviewed separately, leaving the problems of crushing control to other studies.

\subsubsection{Rod/ball mill grinding circuits}

The control strategies of these systems are quite mature, because the control problems are relatively simple. A few numbers of manipulable variables is available: the circuit feed rate and the water addition rates. Normally the water to the rod mill is simply made proportional to the ore feed rate, leaving mainly two control variables: the fresh ore feed rate and the water addition rate to the ball mill circuit. The sump box level is frequently controlled by a local control loop, when a variable-speed pump is available, otherwise it becomes a constraint of the controller. Also the ball mill and the hydrocyclone overflow and underflow densities are frequently processed as operating constraints.

Control strategies are essentially constrained by two control systems where the output variables to be controlled are the PSD and the circulating load, or some other constraints when needed. Classical control methods are quite efficient: SISO decentralized control (Flament, Desbiens, \& del Villar, 1997; Desbiens, Flament, \& Pomerleau, 1997), decoupled control and robust control (Pomerleau, Hodouin, Desbiens, \& Gagnon, 2000), predictive multivariable control (Hodouin, Marcotte, Pomerleau, \& Flament, 1991; Nix, Morrow, \& Gordon, 2000), constrained control with Kalman filter for inference of unmeasured variables (Lestage, Pomerleau, \& Lavoie, 1998), adaptive control (Metzner, 1993; Desbiens, Hodouin, Najim, \& Flament, 1994a; Desbiens, 
Pomerleau, \& Najim, 1994b) and ANN (Thibault, Flament, \& Hodouin, 1991). Methods for realtime maximisation of the throughput based on classical mathematical equations have been recently proposed. They use either supervisory linear programming or dynamic optimisation (Lestage, Pomerleau, \& Hodouin, 2000).

\subsubsection{SAG/FAG milling circuits}

The control problem is more complex than for rod/ball mill grinding circuits, because the state variables, which characterise the mill load, play an essential role in the circuit efficiency. The power drawn by the mill is an increasing and then decreasing function of the mill load. The circuit efficiency is optimal close to the maximum power, on the ascending side of the curve. A sound control strategy requires an inference of the mill load and a supervisory algorithm to maintain the operating point close to the optimum value. Kalman filters are extensively used for load inference (Herbst, Pate, \& Lo, 1993; Broussaud, 1999) coupled to expert systems for control decision making (Bourassa \& Lanthier, 1995; Lestage \& Pomerleau, 1999; Paris \& Cipriano, 1991; Perry \& Hall, 1994; Samskog, Björkman, Söderman, Broussaud, \& Guyot, 1995). These are mature or active techniques.

\subsubsection{Interfacing comminution process with mining and separation}

It is a truism to say that if an ore with perfectly constant properties and throughput was fed to the mill, process control engineers would be unemployed. This is obviously impossible, but this leads to two possible points of view. On the one hand, it is appealing to try storage and blending strategies at the mine-mill interface, for damping the mill feed disturbances. This may lead to improve milling efficiency in the context of low level instrumentation and control. On the other hand, a prior knowledge of the nature of the disturbance coming from the mine would make possible either feedforward optimisation of the milling efficiency, or feedback change of the blasting or crushing operations, at the cost of instrumentation, modelling and control efforts. McKee and Kojovic (1997) mention that blending strategies were able to improve the grinding and flotation efficiencies in a $\mathrm{Cu}-\mathrm{Pb}-\mathrm{Zn}$ operation. Herbst and Blust (2000), as well as McKee, Chitombo and Morrell (1995), also, showed the importance of the blasting and crushing operations on the performance of SAG milling.

\subsection{Flotation process}

A flotation plant, or any other separation plant, has a very few number of output variables defining the operation performance. Usually the concepts of grade and recovery are the two degrees of freedom of the process outputs that are used to describe the targets, despite recovery being essentially a steady-state concept. For given operating conditions, throughput and feed characteristics (particle size, composition and surface activity distributions), there is an upper bound of the feasible region, which is improperly called the grade-recovery curve. A first control task is to locate, on this upper bound, the target corresponding to the maximum revenue. Unfortunately this target moves as the upper bound, the metal market prices (Bazin \& Hodouin, 1997), the throughput, and the feed characteristics move. Several attempts, using expert systems and fuzzy logic, are made for real-time tracking of the target, but they are usually based on heuristics and specific to plants, thus difficult to generalise. 
A second control task is to select the strategy of manipulation of the control variables. The number of manipulated variables is extraordinarily large compared to the two-degree of freedom output (which is in practice one since frequently the target is only moved on the supposedly fixed upper bound in the grade-recovery plane). Most of the time the overall objective is cascaded to the various stages of the flotation plant. Typically, recovery is controlled in the rougher-scavenger stage, while grade is controlled in the cleaner stages. Again the control problem becomes puzzling, since each stage has many manipulable variables (chemical re-agents addition rates, air flowrates, pulp levels, pHs) which are strongly interacting because the chemical reagents used at one location in the circuit flow to the other parts of the circuit. Prior to the implementation of any stabilising control strategy, there is a need for optimal tuning of the redundant manipulable variables, such as the search for the optimal distribution of the reagents along the flotation banks (Bazin, Proulx, \& Hodouin, 1998).

Furthermore, there are circulating streams in a flotation circuit that create strong interactions between the variables. It is so complex to properly manage these circulating loads that some companies (Stowe, 1992) are using more and more open circuit design, although it can be proved that they theoretically decrease the plant metallurgical performance. The reason is that an open circuit is easier to control and thus exhibits better performances than closed circuits which are continuously disturbed by improper control actions (Blakey, Hodouin, \& Bazin, 1995). The problem is still more complex when more than one metal is to be recovered. For instance, in a copper/ lead/zinc operation, the tuning of the various flotation plants should not be independent (Bazin \& Hodouin, 1997) for the selection of the targets of each circuit as well as for the selection of the control actions in the upstream circuits, which also have an impact on the downstream circuits.

Finally, non-linearity of the control actions is a major problem. For instance, the collector concentration does not affect linearly the rate of flotation of the particles. Even more, the effect varies as a function of the particle size. There is usually a plateau in the hydrophobicity/ collector concentration relationship, and even a decrease of hydrophobicity at high concentration. This strong variation of the process gains (including a possible inversion of its sign) is difficult to manage by classical control techniques.

To face those difficult control problems of flotation plants, a wide variety of approaches are applied (mature or active) or in development on simulators (emerging). They are listed briefly below:

- Model predictive SISO control (mature) in Suichies, Leroux, and Dechert (1998);

- Multivariable control: model predictive feedback control (Hodouin et al., 1993a), including predictive feedforward (Hodouin, Gagnon, \& Bazin, 2000); Ding and Gustafsson (1999); for column flotation (del Villar et al. 1999a, b; Desbiens, Hodouin, \& Mailloux, 1998b); mature multivariable level control in Hulbert (1995);

- Non-linear control using mathematical models (Desbiens, del Villar, \& Milot, 1998a; Benaskeur \& Desbiens, 1999);

- Adaptive control (Desbiens et al., 1994a, b); Sbarbaro (1999);

Supervisory expert control: Cipriano, Medina, Martinez, and Gonzales (1991), and for the flotation columns: McKay and Ynchausti (1996), Bergh, Yianatos, and Cartes (1996); Bergh and Yianatos 
(1999);

- Fuzzy control: Carvalho and Durão (1999a, 2000); Hirajima et al. (1991); Osorio, Perez-Correa and Cipriano (1999);

- Artificial Neural Nets: Cotez and Durã0 (1995), and Durão and Cortez (1995);

- Adaptive genetic algorithm: Karr (1996);

- Integration of grinding and flotation control and optimization: Bascur (1991), Pulkkinen, Ylinen, Jämsä-Jounela, and Järvensivu (1993); Sosa-Blanco et al. (2000).

\section{Conclusions}

The main features of MP control are:

- The important physical or chemical properties of the material to be processed are presently impossible to measure on a real-time basis. This is particularly true for the fresh ore feed characteristics (mineral grain size distribution, mineral composition, mineral association, grindability) and the ground material properties (liberation degree, particle composition distribution, particle hydrophobicity);

- On-line measurements of chemical assays, flowrates, percentage of solids, particle size distributions, and equipment hold-up properties can be inaccurate;

- It is still quite difficult to understand the true mechanisms of real flotation plants or SAG milling circuits. As a consequence, fundamental process models are quite difficult to build, most specially for size classification, flotation, and autogenous grinding processes. Furthermore, the modelling of the links between the mine and the mill as well as between comminution and separation processes are still in their infancy;

- In this context, empirical modelling tools are quite attractive, but they have the inherent limitations of empiricism, and require constant adaptation to continuously changing processes and ore properties;

- As a consequence of the above features, plant-wide optimisation is difficult to formulate on an economic basis and obviously yet more complex to implement, although it is the only final goal of this industry, at least in the liberal economy context.

The control fields, which are mature are:

- Expert systems applications

- Steady-state mass balance data reconciliation

- Particle size measurement in the fine size range

- Grinding circuit multivariable stabilising control

- Flotation circuit multi SISO stabilising control.

The active control areas are mainly:

- Froth image analysis

- Supervisory control of FAG/SAG grinding circuit using a combination of estimators and expert systems

- AI applications to flotation and grinding circuit supervision

- Multivariable non-linear control of flotation systems

Emerging techniques are appearing in the following domains: 
- Fast liberation degree measurement

- Fault detection and isolation

- Integration of comminution and separation control

- Multivariate process monitoring techniques

- Interfacing of mining data and concentrator feed-forward control strategies

- On-line use of phenomenological models.

Although it is a major factor in MP control, the human resource aspect has not been discussed in the above survey, because it may vary considerably from country to country, depending on education systems, management strategies and local scientific cultures. Some comments may however be made. Although there is still a lack of sensors in MP plants, it is fair to say that the large databases stored in industrial computers could be used much more efficiently to better understand, control and optimise processes. There is a very significant gap between data and processing tool availability, and actual data exploitation. One factor explaining this underexploitation of process data may be the understandable tendency among industrial decision makers to invest in areas where a return on investment can easily be quantified (e.g. equipment) rather than in more subtle fields, as in data processing know-how, where costs may still be easy to assess (salaries) but where medium to long-term returns on investment are subtly distributed over several process components.

A second human factor can be found in the sometimes rather limited ability of metallurgists and process engineers to use data to increase process efficiency. An explanation is probably related to the Mineral or Metallurgical Engineering curricula which, in most universities, emphasise physicochemistry, mineralogy, metals and materials properties and production technologies and make little provision for the systemic study of plant operations. Engineering students are also taught mathematics, statistics, optimisation and control, but these topics often remain poorly integrated in the main curriculum. Abstract analytical and synthetical reasoning skills seem to be receding and being replaced, in the new information culture of developed countries, by a sometimes impressive but also incoherent empirical knowledge. Yet, the success of process control depends precisely on such skills if process engineers are to meaningfully interlock abstract methods and empirical observations. The importance of honouring and developing those skills, not only in educational programs but also in professional circles can therefore hardly be overemphasised.

\section{References}

Aldrich, C. (1998). Visualization of multivariate data with auto-associate neural networks. Pattern Recognition Letters, 19, 749-764.

Aldrich, C., \& van Deventer, J. S. J. (1994). The use of connectionist systems to reconcile inconsistent process data. The Chemical Engineering Journal, 54, 125-135.

Aldrich, C., \& van Deventer, J. S. J. (1995). Comparison of different artificial neural nets for the detection and location of gross errors in process systems. Industrial and Engineering Chemistry Research, 34, 216-224.

Barbery, G. (1991). Mineral liberation: Measurement, simulation, and practical use in mineral processing. Québec: Les éditions GB.

Bascur, O.A. (1991). Integrated grinding/flotation controls and management. In G. S. Dobby, S. 
A. Argyropoulos, \& S. R. Rao (Eds.), Proceedings of copper 91, Vol. 2, (pp. 411-428). Oxford: Pergamon Press.

Bascur, O.A. (1993). Bridging the gap between plant management and process control. In Scheiner et al. (Eds.), Emerging computer techniques for the mineral industry (pp. 73-81). Colorado: SME, Littleton.

Bascur, O. (2000). An interactive dynamic flotation model framework. In P. Massacci (Ed.), Proceedings of the XXIth IMPC, Vol. 3 (pp. C8a-21-31). Amsterdam: Elsevier.

Bascur, O. A., \& Kennedy, J. P. (1999). Real-time information management for improving productivity in metallurgical complexes. In D. Hodouin, C. Bazin, A. Desbiens (Eds.), Control and optimization in minerals, metals, and materials processing (pp. 3-16). Montréal: Metallurgical Society of the CIM.

Bazin, C., \& Franklin, M. (1996). Real-time material balance for flotation plants using a least-squares recursive algorithm. International Journal of Mineral Processing, 46, 231-244.

Bazin, C., \& Hodouin, D. (1997). Selection of flotation circuit set points as a function of metal prices. Proceedings of the 29th annual meeting of the Canadian mineral processors, CIM, Ottawa (pp. 405- 406).

Bazin, C., Proulx, M., \& Hodouin, D. (1998). Distribution of reagents down a flotation bank. In: Proceedings of the 30th conference of mineral processors. Montréal: CMP-CIM.

Benaskeur, A. R., \& Desbiens, A. (1999). Lyapunov-based decentralized control of a rougher flotation phenomenological simulator. In D. Hodouin, C. Bazin, \& A. Desbiens (Eds.), Control and optimization in minerals, metals, and materials processing (pp. 323- 332). Montréal: Metallurgical Society of the CIM.

Bergh, L., \& Yanatos, J. B. (1999). Supervisory control experience on large industrial flotation columns. In D. Hodouin, C. Bazin, \& A. Desbiens (Eds.), Control and optimization in minerals, metals, and materials processing (pp. 299-310). Montréal: Metallurgical Society of the CIM.

Bergh, L. G., Yianatos, J. B., \& Cartes, F. (1996). Hierarchical control strategy in columns at El Teniente. In C. O. Gomez \& J. A. Finch (Eds.), Proceedings of the international symposium on column flotation, column '96 (pp. 369-380). Montréal: CIM.

Berton, A., \& Hodouin, D. (2000). Statistical detection of gross errors in material balance calculation. In J. A. Herbst (Ed.), CONTROL 2000, mineral and metallurgical processing (pp. 157-166). Denver, Colorado, USA: SME.

Blakey, B., Hodouin, D., Bazin, C. (1995). An assessment of the effects of recirculating loads on the dynamic performance of simple flotation circuit structures. In Mitri, H.S. (Ed.), Proceedings of CAMI '95 (pp. 756-766). Montréal: CIM.

Bonifazi, G., Serranti, S., Volpe, F., \& Zuco, R. (1999). Software sensors, digital imaging based for flotation froth supervision: Algorithm and procedures. In D. Hodouin, C. Bazin, \& A. Desbiens (Eds.), Control and optimization in minerals, metals, and materials processing (pp. 143-146). Montréal: Metallurgical Society of the CIM.

Bourassa, M., \& Lanthier, R. (1995). Grinding circuit optimization at Mine Doyon. Proceedings of the 27th annual meeting of the Canadian mineral processors (pp. 294-310). Ottawa: CIM.

Broussaud, A. (1999). Factors influencing the profitability of optimizing control systems. In D. Hodouin, C. Bazin, \& A. Desbiens (Eds.), Control and optimization in minerals, metals, and materials processing (p. 393). Montréal: Metallurgical Society of the CIM.

Carvalho, M. T., \& Durão, F. (2000). Strategies for fuzzy control of a water/air column. In P. Massacci (Ed.), Proceedings of the XXth IMPC, Vol. 3 (pp. C3-17-23). Amsterdam: Elsevier. 
Cipriano, A., Guarini, M., Soto, A., Briceno, H., Mery, D. (1997). Expert supervision of flotation cells using digital image processing. In Hoberg, H., von Blottnitz, H. (Eds.), Proceedings of the XXth international mineral processing congress, Vol. 1, (pp. 281-292). Aachen, Germany: GDMB.

Cipriano, A., Medina, A., Martinez, C., \& Gonzalez, G. (1991). Supervisor and control strategy for a flotation plant. Proceedings of the IFAC workshop on expert systems in minerals and metals process, Helsinki.

Cortez, L., \& Durão, F. (1995). An expert neural network to control a mineral flotation process. Proceedings of the XXV APCOM, Brisbane (pp. 431-436).

Crowe, M. C. (1996). Data reconciliation - progress and challenges. Journal of Process Control, 6(2/3), 89-98.

Del Villar, R., Grégoire, M., \& Pomerlau, A. (1999a). Control of bias and level in a laboratory flotation column. Proceedings of the 31 st annual meeting of the Canadian mineral processors (pp. 425-442). Ottawa: CIM.

Del Villar, R., Grégoire, M., \& Pomerleau, A. (1999b). Automatic control of a laboratory flotation column. Minerals Engineering, 12(3), 291-308.

Desbiens, A., del Villar, R., \& Milot, M. (1998a). Identification and gain-scheduled control of a pilot flotation column. In Automation in mining, mineral and metal processing. Proceedings of an IFAC symposium (pp. 337-342). Oxford: Pergamon.

Desbiens, A., Flament, F., \& Pomerleau, A. (1997). Distributed control at the Kidd Creek grinding plant - part II: Implementation. CIM Bulletin, 90(1008), 145-150.

Desbiens, A., Hodouin, D., \& Mailloux, M. (1998b). Non-linear predictive control of a rougher flotation unit using local models. In Automation in mining, mineral and metal processing. Proceedings of an IFAC symposium (pp. 297-302). Oxford: Pergamon.

Desbiens, A., Hodouin, D., Najim, K., \& Flament, F. (1994a). Long-range predictive control of a rougher flotation unit. Minerals Engineering, 7(1), 21-37.

Desbiens, A., Hodouin, D., \& Plamondon, E. (2000). Global predictive control: A unified control structure for decoupling set-point tracking, feedforward compensation and disturbance rejection dynamics. IEE Proc. - Control Theory Appl., 147(4), 465-475.

Desbiens, A., Pomerleau, A., \& Najim, K. (1994b). Adaptive predictive control of a grinding circuit. International Journal of Mineral Processing, 41, 17-31.

Ding, L., \& Gustafsson, T. (1999). Modelling and control of a flotation process. In D. Hodouin, C. Bazin, \& A. Desbiens (Eds.), Control and optimization in minerals, metals, and materials processing (pp. 285-298). Montréal: Metallurgical Society of the CIM.

Du, Y. G., del Villar, R., \& Thibault, J. (1997a). Neural net-based soft-sensor for dynamic particle size estimation in grinding circuits. International Journal of Mineral Processing, 52, 121-135.

Du, Y. G., Hodouin, D., \& Thibault, J. (1997b). Use of a novel auto-associative neural network for non-linear steady-state data reconciliation. A.I.Ch.E. Journal, 43(7), 1785-1796.

Durão, F., Cortez, L. A. (1995). Neural network controller of a flotation process. Proceedings of the XIXIMPC, Vol. 1 (pp. 245-250).

Espinoza, P. A., Gonzalez, G. D., Casali, A., \& Ardiles, C. (1995). Design of soft sensors using cluster analysis. Proceedings of the XIXth international mineral processing congress, Vol. 1 (pp. 261-266). Colorado, USA: SME.

Finch, J. A., \& Dobby, G. S. (1990). Column flotation. New York: Pergamon Press.

Finch, J. A., Gomez, C., Hardie, C., Leichtle, G., Filippone, R., \& Leroux, D. (1999). Bubble surface area flux: A parameter to characterize flotation cells. Proceedings of the 31st Annual 
meeting of the CMP (pp. 199-210). Ottawa: CIM.

Flament, F., Desbiens, A., \& del Villar, R. (1997). Distributed control at the Kidd Creek grinding plant - part I: Control strategy design. CIM Bulletin, Vol. 90 (1008) (pp. 139-144).

Flintoff, B. C. (1995). Control of mineral processing systems. Proceedings of the XIX IMPC, Vol. 1 (pp. 15-23).

Garrigues, L., Kettaneh, N., Wold, S., \& Bascur, O. A. (2000). Multivariate real time monitoring using principal component analysis and projection to latent structure. In J. A. Hebst (Ed.), CONTROL 2000, Mineral and metallurgical processing (pp. 41-47). Littleton, Colorado: SME.

Gepford, J. T., Spangler, M., Scott, T., \& Prisbrey, K. A. (2000). Neural network limitations and database requirements. In J. A. Hebst (Ed.), CONTROL 2000, Mineral and metallurgical processing (pp. 117-124). Littleton, Colorado: SME.

Gu, Y., \& Guerney, P. (1999). The presentation of results from the Philipps/JKMRC mineral liberation analyser in a user friendly manner. Mineral Processing '98, Cape Town, South Africa, p. 13.

Herbst, J. A., \& Blust, S. L. (2000). Video sampling for mine-to-mill performance evaluation. J. A. Herbst (Ed.), CONTROL 2000, mineral and metallurgical processing (pp. 157-166). Denver, Colorado, USA: SME.

Herbst, J. A., \& Pate, W. T. (2000). Dynamic flowsheet simulation: A new tool for mine through mill optimization. In P. Massacci (Ed.), Proceedings of the XXIth IMPC, Vol. 1 (pp. A3-6673). Amsterdam: Elsevier.

Herbst, J. A., Pate, W. T., Flores, R. T., \& Zarate, H. A. (1995). Plant-wide control: The next step in mineral processing plant optimization. In Proceedings of the XIXth international mineral processing congress, Vol. 1 (pp. 211-216). Colorado, USA: SME.

Herbst, J. A., Pate, W. T., \& Lo, Y. C. (1993). A model-based methodology for steady-state and dynamic optimisation of autogenous and semi-autogenous grinding mills. Proceedings of the XVIIIth IMPC congress, The Australasian Institute of Minerals and Metals, Sydney, Australia (pp. 519-527).

Hirajima, T., Takamori, T., Tsunekawa, M., Matsubara, T., Oshima, K., Imai, T., Sawaki, K., \& Kubo, S. (1991). The Application of fuzzy logic to control concentrate grade in column flotation at Toyoha mines. Proceedings of international conference on column flotation '91, Sudbury, Canada, Vol. 2 (pp. 375-389).

Hodouin, D., Bazin, C., \& Makni, S. (1997). Dynamic material balance algorithms: Application to industrial flotation circuits. Minerals and Metallurgical processing, 14, 21-28.

Hodouin, D., \& Berton, A. (2000). An algorithm for fault detection and isolation using mass balance constraints. In P. Massacci (Ed.), Proceedings of the XXIth IMPC, Vol 1 (pp. A3-5965). Amsterdam: Elsevier.

Hodouin, D., \& Desbiens, A. (1999). A multi-controller structure for teaching and designing predictive control strategies. In D. Hodouin, C. Bazin, \& A. Desbiens (Eds.), Control and optimization in minerals, metals, and materials processing (pp. 257-270). Montréal: Metallurgical Society of the CIM.

Hodouin, D., Flament, F., \& Bazin, C. (1993a). Predictive control of flotation plants. In Emerging computer techniques for the minerals industry (pp. 3-12). Littleton, Colorado: SME.

Hodouin, D., Gagnon, E., \& Bazin, C. (2000). Feedforward plus feedback predictive control of a simulated flotation bank. Powder Technology, 108, 173-179.

Hodouin D., MacGregor, J., Hou, M., \& Franklin, M. (1993b). Multivariate statistical analysis of mineral processing plant data. CIM Bulletin, 86, 23-34. 
Hodouin, D., \& Makni, S. (1998). Data reconciliation for stationary multi-phase multi-stream metallurgical processes. In Automation in mining, mineral and metal processing. Proceedings of an IFAC symposium (pp. 49-54). Oxford: Pergamon Press.

Hodouin, D., Marcotte, Y., Pomerleau, A., Flament, F. (1991). Predictive control of grinding circuits - An evaluation by dynamic simulation. In G. S. Dobby, S. A., Argyropoulos, S. R. Rao (Eds.), Proceedings of copper 91, Vol. 2 (pp. 377-394). Oxford: Pergamon Press.

Hodouin, D., Mirabedini, A., Makni, S., \& Bazin, C. (1998). Reconciliation of mineral processing data containing correlated measurement errors. International Journal of Mineral Processing, 54, 201-215.

Hulbert, D. G. (1995). Multivariable control of pulp levels in flotation circuits. In Automation in mining, mineral and metal processing. Proceedings of an IFAC symposium (pp. 71-76). Oxford: Pergamon Press.

Hyotyniemi, H., \& Ylinen, R. (1998). Modeling of visual flotation froth data automation in mining, mineral and metal processing. In Proceedings of an IFAC symposium (pp. 309-314). Oxford: Pergamon Press.

Inoue, T., \& Okaya, K. (2000). Micro-scale physical model to account for energy spectrum distribution in the ball mill for sophisticated performance prediction. In P. Massacci (Ed.), Proceedings of the XXIth IMPC, Vol. 1 (pp. A3-16-23). Amsterdam: Elsevier.

Jämsä-Jounela, S.-L. (2000). Current status and future trends in the automation of mineral and metal processing. IFAC Workshop Preprints, Helsinki (pp. 96-108).

Jämsä-Jounela, S.-L., Laine, S., \& Laurila, H. (1999a). Feed type based expert systems in mineral processing plants. In D. Hodouim, C. Bazin, \& A. Desbiens (Eds.), Control and optimization in minerals, metals, and materials processing (pp. 127-142). Montréal: Metallurgical Society of the CIM.

Jämsä-Jounela, S.-L., Toth, S., Kuitunen, T., \& Kampe, J. (1999b). Fault diagnosis module of the intelligent control system for the variable volume pressure filter. Proceedings of IFAC World Congress, Beijing, People's Republic of China.

Karr, C. L. (1996). Strategy for adaptive process control for a column flotation unit. In R. V. Ramani (Ed.), Proceedings of the 26th APCOM symposium (pp. 303-307). Colorado, USA: SME.

Kelly, E. G. (1991). The evaluation of separation efficiency. In D. Malhotra, R. R. Klimpel, A. L. Mular (Eds.), Evaluation and optimisation of metallurgical performance (pp. 239-252). Littleton, Colorado: SME Inc.

King, R. P., \& Schneider, C. L. (2000). Mineral liberation analysis - A review of some recent developments. In P. Massacci (Ed.), Proceedings of the XXIth IMPC, Vol. 1 (pp. A2-16-23). Amsterdam: Elsevier.

Laine, S., Lappainen, H., \& Jämsä-Jounela, S.-L. (1995). On-line determination of ore type using cluster analysis and neural networks. Minerals Engineering, 8, 637-648.

Leroux, D., \& Franklin, M. (1994). A methodology for on-stream XRF analyzer calibration using statistics. In Innovations in mineral processing (pp. 461-474). Ottawa: CIM.

Lestage, R., \& Pomerleau, A. (1999). Pole-placement optimizing controller and application to a simulated autogenous grinding circuit p. 453. Proceedings of the 31 st annual meeting of the Canadian mineral processors (pp. 389-410). Ottawa: CIM.

Lestage, R., Pomerleau, A., \& Hodouin, D. (2000). Constrained realtime optimisation of a grinding circuit using steady-state linear programming supervisory control. Powder Technology, in press. Lestage, R., Pomerleau, A., \& Lavoie, G.J. (1998). Advanced control of an industrial closed-loop 
grinding circuit. In Automation in mining, mineral and metal processing. Proceedings of an IFAC symposium (pp. 7-12). Oxford: Pergamon Press.

Lo, Y. C., Oblad, A. E., \& Herbst, J. A. (1996). Cost reduction in grinding plants through process optimisation and control. Minerals and Metallurgical Processing, 8, 19-21.

Maerz, N. H., \& Palangio, T. C. (2000). On-line fragmentation analysis for grinding and crushing control. In J. A. Hebst (Ed.), CONTROL 2000, Mineral and Metallurgical Processing (pp. 109116). Littleton, Colorado: SME.

Makni, S., \& Hodouin, D. (1994). Recursive BILMAT algorithm: An on-line extension of data reconciliation techniques for steady-state bilinear material balance. Minerals Engineering, 7(9), $1179-1191$.

Makni, S., Hodouin, D., \& Bazin, C. (1995a). On-line data reconciliation by minimization of a weighted sum of squared residuals and node imbalances. Proceedings of the XIXth international mineral processing congress, Vol. 1 (pp. 233-237). Colorado, USA: SME.

Makni, S., Hodouin, D., \& Bazin, C. (1995b). A recursive node imbalance method incorporating a model of flowrate dynamics for on-line material balance of complex flowsheets. Minerals Engineering, 8(7), 753-766.

McKay, J. D., \& Ynchausti, R. A. (1996). Expert supervisory control of flotation columns In C. O. Gomeze, \& J. A. Finch (Eds.), Proceedings of the international symposium on column flotation, column '96 (pp. 353-367). Montre'al, CIM.

McKee, D. J., Chitombo, G. P., \& Morrell, S. (1995). The Relationship between Fragmentation in Mining and Comminution circuit Throughput. Minerals Engineering, 8(11), 1265-1274.

McKee, D. J., \& Kojovic, T. (1997). Comminution in a mining context. In S. K. Kawatra (Ed.), Comminution Practices (pp. 271-278). Littleton, Colorado: SME.

Metzner, G. (1993). Multivariable and optimising mill control - the south african experience. Proceedings of the XVIIIth IMPC congress, The Australasian Institute Of Minerals and Metals, Sydney, Australia (pp. 293-300).

Mirabedini, A., \& Hodouin, D. (1998). Calculation of variance and covariance of sampling errors in complex mineral processing systems, using state-space dynamic models. International Journal of Mineral Processing, 55, 1-20.

Morrison, R. D. (1993). Concentrator optimisation. Proceedings of the XVIII international mineral processing congress, Sydney (pp. 483-489).

Morrison, R. D. (2000). Applying image analysis to process control from blasting to flotation. In J. A. Hebst (Ed.), CONTROL 2000, mineral and metallurgical processing (pp. 51-58). Littleton, Color-ado: SME.

Moys, M. H., van Nierop, M. A., van Tonder, J. C., \& Glover, G. (2000). Validation of the discrete element method by comparing predicted load behaviour of a grinding mill with measured data. In P. Massacci (Ed.), Proceedings of the XXIth IMPC, Vol. 3 (pp. C3-39-44). Amsterdam: Elsevier.

Narasimhan, S., \& Jordache, C. (1999). Data reconciliation and gross error detection: An intelligent use of process data. Houston, Texas: Gulf Pub. Cy.

Nikolov, J., \& Madsen, I. (2000). On-line XRD analysers for slurry samples. In P. Massacci (Ed.), Proceedings of the XXIth IMPC (pp. A1-30-37). Amsterdam: Elsevier.

Nix, A., Morrow, A., \& Gordon, L. (2000). Using multivariable predictive control to optimize the ASARCO Mission mill. In J. A. Hebst (Ed.), CONTROL 2000, mineral and metallurgical processing (pp. 201-207). Littleton, Colorado: SME.

Osorio, P., Perez-Correa, J. R., \& Cipriano, A. (1999). Assessment of expert fuzzy controllers for 
conventional flotation plants. Minerals Engineering, 12(11), 1327-1338.

Paris, A., \& Cipriano, A. (1991). Supervisor expert control of a semi autogenous grinding circuit. Proceedings of the IFAC Workshop on Expert Systems in Minerals and Metals Processes, Helsinki.

Pérez, R., del Villar, R., \& Flament, F. (1993). Level detection in a flotation column using an artificial neural network. Proceedings of the 24th APCOM, Vol. 3 (pp. 174-181).

Perry, R., \& Hall, M. (1994). Les mines selbaie semi-autogenous grinding circuit expert system. Proceedings of the 26th annual meeting of the Canadian mineral processors, paper no. 18. Ottawa: CIM.

Perry, R., Supomo, A., Mular, M., \& Neale, A. (2000). Monitoring control loop health at P.T. Freeport Indonesia. In J. A. Hebst (Ed.), CONTROL 2000, mineral and metallurgical processing (pp. 71-82). Littleton, Colorado: SME.

Pomerleau, A., Hodouin, D., Desbiens, A., \& Gagnon, E. (2000). A survey of grinding circuit control methods: From decentralized PID controllers to multivariable predictive controllers. Powder Technology, 108, 103-115.

Pulkkinen, K., Ylinen, R., Jämsä-Jounela, S.-L., Järvensivu, M. (1993). Integrated expert control system for grinding and flotation. Proceedings of the XVIIIth IMPC congress, The Australasian Institute Of Minerals and Metals, Sydney, Australia, pp. 325-334.

Romagnoli, J. A., \& Sanchez, M. A. (2000). Data processing and reconciliation for chemical process operation. San Diego, California: Academic Press.

Samskog, P. O., Björkman, Söderman, P., Broussaud, A., \& Guyot, O. (1995). Model-based and expert supervisory control at Kiruna LKAB concentrators-Sweden. Proceedings of the XIXth international mineral processing congress, Vol. 1 (pp. 217-224). Colorado, USA: SME.

Sbarbaro, D. (1999). Adaptive non-linear predictive control of a simulated flotation cell. In D. Hodouin, C. Bazin, \& A. Desbiens (Eds.), Control and optimization in minerals, metals, and materials processing (pp. 311-321). Montréal: Metallurgical Society of the CIM.

Schena, G. D., \& Gochin, R. J. (2000). Identification of the distributed efficiency of a particle separation system. In P. Massacci (Ed.), Proceedings of the XXIth IMPC, Vol. 1 (pp. A346-53). Amsterdam: Elsevier.

Sosa-Blanco, C., Hodouin, D., \& Bazin, C. (1999). Integrated simulation of grinding and flotation. Application to a lead-silver ore. Minerals Engineering, 12(8), 948-968.

Sosa-Blanco, C., Hodouin, D., Bazin, C., Lara-Valenzuela, C., \& Salazar, J. (2000). Economic optimisation of a grinding and flotation plant. Minerals Engineering, 13(10-11), 999-1018.

Spencer, S.J., Campbell, J.J. Weller, K.R., \& Liu, Y. (2000). Monitoring of SAG mill performance using acoustic emissions. In P. Massacci (Ed.), Proceedings of the XXIth IMPC, Vol. 1 (pp. A413-20). Amsterdam; Elsevier.

Spencer, S.J., \& Sutherland, D. (2000). Stereological correction of mineral liberation grade distributions. In P. Massacci (Ed.), Proceedings of the XXIth IMPC, Vol. 1 (pp. A2-1-8). Amsterdam: Elsevier.

Spring, R. (1996). Minimum variance as a benchmark for feedback control. TAPPI Journal, 3(5), 97-101.

Stanfelj, N., Marlin, T. E., \& MacGregor, J. F. (1993). Monitoring and diagnosing process control performance: The single loop case. Industrial and Engineering Chemistry Research, 32, 301.

Stange, W. (1991). The control of mineral processing plants using neural networks techniques. Proceedings of the IFAC workshop on expert systems in Minerals and Metals Processes, Helsinki. 
Stowe, K. G. (1992) Noranda's approach to complex ores - present and future. AMIRA Annual Technical Meeting, Australia.

Suichies, M., Leroux, D., \& Dechert, C. (1998). An implementation of generalized predictive control in a flotation plant. In Automation in mining, mineral and metal processing. Proceedings of an IFAC symposium (pp. 425-442). Oxford: Pergamon Press.

Tano, K., Samskög, P.O., Gärde, J.C., Skagerberg, B. (1993). PLS modelling of process data at LKAB. Predicting chemical assays in iron ore for process control. In J. Elbrond, X. Tang (Eds.), Proceedings of the XXIV APCOM, Vol. 3 (pp. 259-266). Montréal: CIM.

Thibault, J., Flament, F., \& Hodouin, D. (1991). Modelling and control of mineral processing plants using neural networks. Proceedings of the IFAC workshop on expert systems in Minerals and Metals Processes, Helsinki.

Valery, W., \& Morrell, S. (1995). The development of a dynamic model for autogenous and semiautogenous grinding. Minerals engineering conference '95, St. Ives, England, Vol. 8(11) (pp. 1285-1297).

Van Deventer, J. S. J., Bezuidenhout, M., \& Moolman, D. W. (1997). On-line visualisation of flotation performance using neural computer vision of the froth texture. In Hoberg, H., \& von Blottnitz, H. (Eds.), Proceedings of the XXth international mineral processing congress, Vol. 1 (pp. 315-326). Aachen, Germany: GDMB.

Yoon, R. H. (2000). The role of surface forces in flotation kinetics. In Massacci, P. (Ed.), Proceedings of the XXIth IMPC, Vol. 2 (pp. B8a-1-7). Amsterdam: Elsevier. 